\title{
Back to the Future: Democratic Responsiveness and the Estimation of Future Public Opinion ${ }^{12}$
}

\author{
Eric Merkley ${ }^{3}$ \\ Department of Political Science \\ University of British Columbia \\ Email: eric.merkley@alumni.ubc.ca \\ Address: C425-1866 Main Mall \\ Vancouver, BC, Canada V6T 1Z1 \\ Andrew Owen \\ Department of Political Science \\ University of British Columbia \\ Email: andrew.owen@ubc.ca \\ Address: C425-1866 Main Mall \\ Vancouver, BC, Canada V6T 1Z1 \\ ***Forthcoming in the International Journal of Public Opinion Research***
}

\begin{abstract}
Research on the responsiveness of policy to public opinion has infrequently confronted the possibility that re-election seeking politicians' policy choices may reflect their expectations about future public opinion. This paper reports observational and experimental findings from a survey of senior Canadian policy makers. Results from vignette-based experiments that manipulate the characteristics of current and estimates of future opinion show that policy makers are responsive to the estimated direction of future opinion, but this relationship is conditional on high estimated future salience. Survey results shed additional light on the role that estimates of future opinion play in policy making. Combined, these experimental and observational results suggest existing empirical work on policy responsiveness is incomplete.

\footnotetext{
${ }^{1}$ Many thanks to Laura Stephenson, Fred Cutler, and Dominik Stecula for helpful comments and suggestions. This work was supported by the Social Sciences and Humanities Research Council of Canada [grant number F11-00438].

2 Supplementary materials and replication data and code are available on the author's website (www.ericmerkley.com)

${ }^{3}$ Corresponding author
} 
Scholarly understanding of public opinion's impact on policy making has developed considerably in recent decades. This important and compelling literature, however, does not often account for the fact that electoral incentives complicate the temporal relationship between opinion and policy. Empirical tests of policy responsiveness implicitly adopt a basic model of democracy in which elected officials respond to the state of public opinion at the time of a policy choice (e.g. Burstein, 2003; Miller \& Stokes, 1978; Page \& Shapiro, 1983). Once we acknowledge that most politicians seek re-election (Mayhew, 1974), it becomes clear that policy makers will be more concerned with the state of public opinion at the time of the next election than with public sentiment when policy choices are made. As such, a disconnect between contemporaneous public opinion and policy choices may not necessarily reflect some sort of democratic deficit. Rather, myopic and variable public opinion (Achen \& Bartels, 2016) combine with electoral incentives to motivate elected policy makers to incorporate estimates of future public opinion in their policy choices (Key, 1961).

The significant role anticipated public opinion can play in policy-making is not new but remains under studied. V.O. Key highlights this policy-making factor in his discussion of latent opinion (Key, 1961). In the half-century since, the volume and sophistication of empirical studies of policy responsiveness to public opinion have increased substantially; but tests of the role estimated future opinion plays are few. The difficulty of empirically testing claims about anticipated opinion offers a compelling explanation for the state of the literature (Zaller, 2003). This paper responds to Zaller's call for researchers to better account for anticipated public opinion in studies of democracy and policy making.

This paper does so by drawing on a unique survey of experienced political advisors. First, responses from current and former policy advisors to Canadian federal and provincial cabinet ministers provide new and compelling insights into how policy makers incorporate public opinion into their decision making.

Analysis of their responses reveal that they regard estimated future opinion as more important in policy decisions than contemporaneous public opinion, particularly when salience is expected to be high. They attempt to anticipate this opinion through an analysis of which citizens are likely to win and lose from a policy proposal, the reaction of interest groups, and the general fit of a policy with their party's principles and brand. These surprisingly frank assessments from policy advisors about the relationship between public opinion and policy making provide valuable insights that can shape future research that attempts to incorporate latency and the expectation of future public opinion into studies of democratic responsiveness. 
Second, this paper presents findings from an experiment testing the impact that expectations about future public opinion have on policy choices. This analysis provides experimental evidence of policy responsiveness to the expectation of the salience and direction of future public opinion that echo the positions voiced by our survey respondents.

\section{Anticipating the Direction and Salience of Future Public Opinion}

Democracy is grounded in a link between public opinion and public policy. The nature of that link is the subject of rich theoretical and empirical literatures. The core question in this work is the extent to which public policies reflect public opinion. Particularly in the United States, a number of scholars have attempted to quantify the responsiveness of public policy to issue-based public opinion (e.g., Burstein, 2003; Miller \& Stokes, 1978; Page \& Shapiro, 1983) or policy mood (Erikson, Mackuen, \& Stimson, 2002; Stimson, Mackuen, \& Erikson, 1995). This work has found evidence of substantial, if imperfect, responsiveness of public policy to public preferences across a wide range of issues (see Erikson [2015] and Shapiro [2011] and for reviews of the literature).

Unfortunately, empirical work assessing policy responsiveness almost exclusively conceptualizes it as the tendency for policy to reflect public opinion at the time the decision is made, or, to incorporate time for policy passage, even public opinion in the past. This assumption is problematic because politicians have strong incentives to care more about public opinion on an issue at election time. V.O Key forcefully articulated this point well in advance of empirical studies of representation: "if a legislator is to worry about the attitude of his district, what he needs really to worry about is, not whether his performance pleases the constituency at the moment, but what the response of his constituency will be in the next campaign when persons aggrieved by his position attack his record" (1961, p. 499). It is not obvious why responsiveness to the former over the latter should be seen as a lack of democratic responsiveness. In short, current approaches to measuring policy responsiveness do not take seriously enough politicians' office-seeking nature (Mayhew, 1974). Policy choices may reflect public opinion at the next election or at least policy maker expectations of such opinion. We use our elite survey to shed light on this question:

RQ1: How important are beliefs about future public opinion in the policy process? How does this compare to public opinion at the time of a policy decision?

Key's work has failed to get traction in a research field that overwhelmingly pays attention to public attitudes contemporaneous with policy decisions. In an important exception, Zaller (2003) 
attempted a research revival by drawing attention to evidence of responsiveness to latent opinion in presidential decisions. The crux of Zaller's argument rests on presidential knowledge of some wellknown regularities in the public's response to events: electoral punishment for a poor economy (Fiorina, 1981); the rally around the flag effect (Mueller, 1994); and public resistance to mounting casualties in armed conflict (Mueller, 1973; Zaller, 1995). Presidents use these regularities to anticipate public opinion at the time of the next election. While Zaller is interested in certain predictable latent tendencies in public opinion that have implications for future opinion, Key's focus is on the dynamics that arise from policy decisions that can shape public opinion, such as the reaction of the opposition. Both, however, are united in their belief that policy makers are interested in information that helps them form expectations about public opinion at election time.

That being said, how exactly would a policy maker anticipate the likely dynamics that follow from the adoption of a policy? Scholars have shown that policy makers rely on a number of sources beyond public opinion polls to estimate current opinion, such as interest groups, the news media, and other elected officials (Herbst, 1993; Powlick, 1996). They do not form these estimates accurately, however (Broockman \& Skovorn, 2018). There is likely to be even more error in policy maker estimates of future opinion. Nevertheless, if they do try to make the effort, it is important to know what kinds of information they rely on for this complicated task, which leads to our second research question:

RQ2: What sources of information do policy makers use to estimate future public opinion?

There are good reasons why prevailing literature has focused on public opinion at the time of a decision. We do not have access to policy maker estimates of future public opinion, nor do we know what information they may use to form such estimates. Moreover, contemporaneous public opinion is likely an ineffective proxy for future opinion - especially when voters experience policy consequences different from what they expected. In short, while the use of contemporaneous opinion makes sense, exploring the role of expectations about future opinion represents an important and novel contribution to the study of democratic responsiveness.

The re-election imperative is surely important in understanding some of the variation in democratic responsiveness observed in existing work on topic. For example, policy responsiveness tends to be stronger under conditions of high salience (Canes-Wrone \& Shotts, 2004; Lax \& Phillips, 2009; Page \& Shapiro, 1983). Re-election concerns also explain why U.S. policy better reflects the 
preferences of wealthy citizens as campaign donations are a critical factor for re-election (Bartels, 2008; Gilens, 1995; Gilens \& Page, 2014). We would also expect an imperfect observed link between policy responsiveness and public opinion if policy is created in response to public opinion at $t+1$ rather than t. Specifically, there may be instances where opinion change over time is larger or smaller. Moreover, the normative implications of moderate responsiveness to current opinion are significant. We might not be giving politicians a fair shake by failing to take account of their, surely imperfect, estimates of future electoral opinion.

This paper argues that analyses of policy responsiveness must pay greater attention to the estimated direction of future opinion. Re-election is central to this claim. Elected officials wishing to remain in office should be ultimately concerned with public opinion at election time. Our survey of elite policy makers can help to shed light on our research questions of interest, but we cannot take their word at face value that future public opinion matters in policy making. So, we expose them to hypothetical policy making scenarios carefully designed to draw out possible responsiveness to future public opinion.

Expectations about how the public will feel about a policy choice in the future are, of course, only one of many factors that figure in policy choices. For our purposes, we draw a distinction between the opinion of the broad public and all other considerations including ideology, past promises, as well as the recommendations from interest groups, the bureaucracy, and other experts. In our experimental test we want to hold constant this constellation of factors, which we refer to as policy priors. Predictions about the impact of estimated future opinion are straightforward: policy makers will adjust their policy choices to coincide with future directional opinion. Our first hypothesis is thus:

H1 (Unconditional Responsiveness): Policy makers will be responsive in their policy decisions to the estimated direction of future public opinion with current opinion held constant.

Direction, however, is unlikely to be the only feature of public opinion of interest to policy makers. Issue salience is also likely to be critical. Salience refers to the level of cognitive and behavioral engagement with a policy issue. For our purposes, the central feature of salience is that the concern about, and/or attention to, an issue results in citizens placing substantial weight on the topic when making a vote choice (for more on defining and measuring salience, see: Miller, Krosnick, \& Fabrigar, 2016, and Wlezien, 2005). Salience, of course, varies over time (see Daw, Morgan, Thompson, \& Law, 2013; Downs, 1972; Holt \& Barkemeyer, 2012; Petersen, 2009). Accordingly, we must come to grips, 
not just with policy makers' expectations for future directional opinion, but their expectations about the public's future agenda as well. Therefore, we are also interested in estimated future salience - or the anticipated importance of a policy decision at the time of the next election.

In general, re-election seeking politicians will be more responsive to public opinion, current or future, when an issue commands the sustained attention of the broad public. This claim is well supported by empirical literature on policy responsiveness to contemporaneous public opinion is more robust when salience is high (Canes-Wrone \& Shotts, 2004; Lax \& Phillips, 2009; Page \& Shapiro, 1983; Soroka, 2007; Soroka \& Wlezien, 2005). What role does salience play when we account for the estimated direction of future opinion?

We assert that the moderating impact of salience on responsiveness critically depends on whether future opinion will be supportive of elected officials' policy priors. When the constellation of policy-relevant factors, that we call prior preferences, recommend a policy choice that the public will also support at the time of the next election, there is little reason for politicians to be responsive to future salience. Strong future support is a sufficient condition for a politician to pursue their prior preferences. In contrast, when elected officials expect public opposition in the future; salience matters. In those instances, low anticipated salience suggests public opposition will translate into only a few lost votes. Conversely, high estimated salience and public opposition presents a considerable electoral problem. This discussion motivates our second hypothesis:

H2 (Conditional Responsiveness): Estimated future opposition to a policy option will have a greater effect on elected policy-makers' choices when estimated future salience is high.

\section{Data}

The largely sparse theoretic and empirical literature on estimated future opinion and policy making is, in part, a product of the methodological challenges associated with studying it. In addition to the difficulty of measuring politicians' anticipation of future opinion, it is also exceptionally hard using observational data to tease out the independent effects of estimated future opinion versus current opinion, salience versus direction, as well as separating those factors from policy maker preferences. Further, if politicians are good at anticipating future public opinion, we will not observe cases where they fail to account for it (Zaller, 2003). We need micro-level evidence of a possible causal association between the estimated direction and salience of future opinion and policy decision making. 
Thus, this paper adds to a body of experimental research involving elites (Butler \& Nickerson, 2011; Nyhan \& Reifler, 2015; Sheffer \& Loewen, 2019; Walgrave, Sevenas, \& Loewen, 2018).

In addition to experiments aimed at testing our basic theoretic claims, we also contribute to research on policy responsiveness with original observational data about policy-makers attitudes towards the policy process. Specifically, we use our survey of elites to shed light on other important questions that have been underexplored in literature on public opinion and policy making. Findings from the survey can be usefully incorporated into future efforts to address the role of expectations of future public opinion.

\section{Sample Composition and Recruitment}

Our data comes from a sample of 153 senior policy advisors to Canadian federal or provincial cabinet ministers. In contrast to other studies of political decision-making which focus on elected officials, our sample includes unelected senior political staff. Our interest in the role of estimated future opinion as an input into the policy process motivates our decision to sample from this population.

Parliaments in Westminster systems, such as Canada's, can be seen as "arena" legislatures that serve to represent and articulate the demands of societal forces with little opportunity for individual legislators to influence policy directly (Franks, 1987; Polsby, 1975; Thomas, 2010). This is not to say that backbench MPs have no influence on policy. They do exercise some indirect influence through caucus meetings and more prominently through Private Members' Business, which has been increasing in influence recently (Blidook, 2010, 2012). Nonetheless, decisions about policies are primarily made in executive organizations including cabinet, ministers' offices, and the prime minister's office (Savoie, 2008; White, 2005) and strong party discipline ensures backbench government legislators reliably support decisions made in the executive (Godbout \& Høyland, 2013; Kam, 2009). While a sample of former ministers would be interesting, the population is small and response rates would likely be low. We therefore surveyed individuals who work(ed) for ministers in a policy advisory capacity at the federal and provincial level. These chiefs of staff and policy advisors, among others, have direct experience in the policy making process. They participate in deliberations over policy and provide related advice to their respective ministers on important files. In this sense they are much like senior political staff advising legislators and executives anywhere in the democratic world. 
Access to this ideal population of policy advisors is a challenge. Political advisors are more difficult to identify and locate than politicians. Consequently, we conducted a snowball sample during which respondents are asked to recruit new respondents from among their acquaintances (Goodman, 1961). This technique allows researchers to tap into social networks of typically hard to recruit respondents to gather a reasonably large sample that would otherwise be infeasible (Faugier \& Sargeant, 1997; Thompson, 1997). There are, of course, important limitations to snowball sampling. As a form of non-probability sampling it is prone to bias, particularly of selection. It will over-represent people well connected in social circles and underrepresent those that are not (Griffiths, Gossop, Powis, \& Strang, 1993). The representativeness of the sample is also dependent on the initial respondents who take the survey. Nonetheless, it remains the best way to survey hard to reach populations.

We distributed our survey first to acquaintances who held senior roles in ministries and first ministers' offices. Recruitment continued as participants were encouraged to forward the recruitment email to others they believed would qualify (i.e. having counselled ministers in a policy advisory capacity). Respondents were under instruction not to divulge the specific contents of the study to their contacts and all received $\$ 100$ in compensation. Our initial sample had 166 individuals and we excluded 13 people whose self-reported work experiences indicated they did not serve in a policy advisory role. This left us with a sample of 153 individuals.

The bulk of our sample is comprised of former ministry staff for provincial and federal Conservative parties (65\%), while the remainder worked for provincial and federal Liberal parties. As a result, our sample tilts to the (Canadian) right, averaging 6.5 on a self-reported 0-10 ideology scale (Standard Deviation=1.98). Our sample has a fair degree of variance on political experience. Only $14 \%$ of the sample has between 1 and 2 years of experience. $55 \%$ have over 5 years of experience, with 9\% having over 10 years. 62 percent have worked in an explicit policy advisory capacity. Our sample is split evenly between federal (41\%) and provincial staff (41\%) with the remainder having worked for both.

Although our sample tilts to the right, treatment effects do not vary by party or ideology and pairwise correlations between our survey results and ideology are low to non-existent. The same is true for level of experience and level of government. We therefore believe our sample gives us a reasonable picture of how Canadian partisan ministry staffers view public opinion and policy making - at least during times of majority government. It is possible the distinction between current and future opinion disappears during minority governments. Policy makers may not feel the need to form 
expectations of future public opinion since an election could be around any corner in these contexts. And, of course, generalization beyond the Canadian case should be pursued with caution.

\section{Attitudes towards Public Opinion in the Policy Process}

We first discuss some of the survey results that shed light on our research questions before outlining the design of the experiments. To date, there is little research on the factors that shape policy maker expectations about future opinion. Our survey employs a range of closed and open-ended questions to shed light on: the relative importance of current and future opinion in policy, stability and change in opinion, and the sources of information elites use to estimate future opinion.

Our respondents generally see public opinion as a moderate influence on policy making process conditional on two factors. ${ }^{4}$ First, electoral timelines matter with opinion being a more important consideration late in the electoral cycle. Second, respondents noted variation in the persuadability of the public on different issues. For the most part, they see public opinion as dynamic and open to being changed by both themselves and their opponents, albeit not always successfully. In short, they strongly believe political staff have the ability to persuade the public so long as they are willing to commit resources to the cause. They do not see such behavior as elite manipulation (see Jacobs and Shapiro 2000), but rather as persuasion. Whether they actually have such ability is an open question. Nonetheless, if policy makers do believe they can shape public opinion we should expect less adherence to contemporaneous policy opinion.

\section{Current or Future Opinion?}

Our respondents clearly believe public opinion is dynamic and open to change. As a result, it is not surprising that they also indicate greater attentiveness to possible future opinion than to public opinion at the time policy choices are made. On an 11 point scale respondents rated the relative importance of public opinion when a decision is made (0) versus expected public opinion at the next election (10). With a mean rating of nearly 7 , respondents clearly indicated greater concern with election-proximate opinion (Mean=6.92, Standard Deviation=1.62). Only 12\% of the sample view current opinion as more important with $76 \%$ selecting a number from 6 to 8 .

\footnotetext{
${ }^{4}$ Results of a closed ended question ranking factors in importance in the policy process can be found in Table A1 in the supplementary materials. Public opinion was ranked on par with advice from civil servants and experts.
} 
Open-ended responses indicate participants believe current opinion is only relevant proximate to an election and that election-proximate opinion is less important in the context of low anticipated salience. They also noted, however, that anticipating the issues that will capture the public's imagination is no easy task. Anticipating issue attention is often times as challenging as anticipating the direction of public opinion come election time.

\section{Estimating Future Opinion}

The most obvious shortcut policy makers can take to estimate future opinion is to rely on current opinion. In the face of uncertainty, current opinion can provide an important proxy for future opinion, provided there is often some stability. Respondents believe that public opinion is usually stable. We asked how often current opinion reflects future opinion (almost always, about half the time, less often than not, almost never) and only $29 \%$ of the sample reported that they believe public opinion changes on issues 'more often than not', while not a single respondent indicated a belief that it changed 'almost always'.

Table 1. Sources of Information for Estimates of Future Opinion

\begin{tabular}{|c|l|c|c|}
\hline Rank & \multicolumn{1}{|c|}{ Information Source } & Mean & SD \\
\hline 1 & The fit between the policy and your party leader's brand & 3.38 & 2.55 \\
\hline 2 & Stakeholder group leaders' suggestions about future support & 4.42 & 2.38 \\
\hline 3 & Recommendations from people with substantial political experience & 4.73 & 2.45 \\
\hline 4 & $\begin{array}{l}\text { Reports on public reactions in other jurisdictions that made similar } \\
\text { policy choices }\end{array}$ & 4.75 & 2.80 \\
\hline 5 & $\begin{array}{l}\text { The public's general mood when it comes to whether the } \\
\text { government should generally be doing more or less }\end{array}$ & 5.44 & 2.70 \\
\hline 6 & Tone of media coverage while developing policy & 5.55 & 2.66 \\
\hline 7 & Correspondence from constituents & 6.33 & 2.73 \\
\hline 8 & Polling experts claims about opinion in the future & 6.66 & 2.94 \\
\hline 9 & Strength of opposition to the proposal in the legislature & 7.22 & 2.68 \\
\hline 10 & Opinion editorials while developing policy & 7.72 & 2.27 \\
\hline
\end{tabular}

While stability is usually assumed, it is clear our respondents do believe public opinion is often open to change. This potential for change raises questions about how policy makers estimate future electoral opinion. We asked respondents: "When making policy choices, current opinions polls may not detect how people will feel about a policy decision in the future. We are interested the types of information you might use to anticipate future public opinion" and asked them to rank ten options. 
The results are shown in Table 1. Fit between a policy and the party's brand is by far the most important factor $(\mathrm{M}=3.38$; $\mathrm{SD}=2.55)$. That is, our respondents believe the public - and specifically their party's voter coalition - will care if a government's policy goes against their party's commitments. This factor is followed by advice from stakeholders (i.e. interest groups; $M=4.42 ; \mathrm{SD}=2.38$ ). Less important were the strength of opposition in the legislature $(\mathrm{M}=7.22 ; \mathrm{SD}=2.68)$, and op-eds $(\mathrm{M}=7.72$; $\mathrm{SD}=2.27)$. Our respondents did not view constituent correspondence as particularly important $(M=6.33 ; S D=2.73)$, but see the advice of pollsters as equally inconsequential $(M=6.66 ; S D=2.66)$.

Open-ended responses make clear that policy-specific details are critical in estimating future opinion. Our respondents expect their party's voter coalition to turn against policy that flies against the brand of the leader and her party. More broadly, many respondents indicated that policy costs and benefits are helpful when predicting future opinion. Direct experience with policy means that its consequences often drive future opinion.

Polling, surprisingly, plays a fairly modest role in the process of estimating future and current opinion. Respondents noted that polling is rarely available for most policy issues, particularly polling segmented enough to tap into the voters they were most concerned about, such as their electoral coalition. Others expressed skepticism of the entire enterprise citing recent unreliability.

\section{Experimental Design}

The descriptive survey findings provide some compelling suggestive evidence that policy makers try to anticipate and respond to future, salient public opinion (H2). Our experiments were designed to confirm this mechanism with experimental vignettes. Respondents read three vignettes of policy scenarios in the experiment. Table 2 provides an outline of these vignettes and the dimensions of experimental manipulation. Detailed text appears in the supplementary materials. Vignettes 1 and 2 describe two fictitious policy scenarios after which respondents made a policy recommendation to their minister. Recommendations involved selecting between two policy options. The first option is supported by the civil service and aligns with their party's principles and allied political groups. The logic here is that these 'good policy' options should, in the absence of other information, be strongly preferred to the second policy choice in each case. After each vignette, respondents indicated which option they would prefer and the strength of their recommendation. Our dependent variables are the resulting nine-point scales, rescaled so that ' 1 ' indicates very strong support for the 'good policy' option, and ' 0 ' indicates the opposite. 
Table 2. Vignette Design

\begin{tabular}{|c|c|c|c|}
\hline & $\begin{array}{c}\text { Vignette 1 } \\
\text { (Fast Finish vs. Jump Start) }\end{array}$ & $\begin{array}{c}\text { Vignette 2 (Aspire } \\
\text { v. Secure) }\end{array}$ & $\begin{array}{c}\text { Vignette 3 } \\
\text { (TFW) }\end{array}$ \\
\hline Control & Oppose/Salient (28) & Oppose/Salient (36) & Ambivalent (42) \\
\hline Treatment 1 & Support (37) & Non-salient (47) & Oppose/Salient (43) \\
\hline Treatment 2 & Oppose/ Non-Salient (36) & Salient (45) & Oppose/Non-salient (43) \\
\hline Treatment 3 & Oppose/Salient (27) & N/A & N/A \\
\hline
\end{tabular}

Note: Cell contents present the direction and/or salience of public opinion depicted in the experimental conditions. The control condition only features information on current opinion. Treatment conditions receive the same information as control plus additional information on future opinion. Sample sizes in parentheses after excluding respondents who failed all three screener questions. TFW $=$ Temporary Foreign Workers.

The political issue and policy area were not mentioned in both Vignettes 1 and 2. We did so to diminish the impact of other factors, such as prior experience with an issue or respondents' own political preferences. Absent information of this sort, participants must rely solely on the policy attributes we identify, including the state of public opinion. Our aim here is to establish the presence of a causal effect rather than to estimate the magnitude of effects in real world situations. Experiments of this sort are well suited to identify the former. Nonetheless, we added an additional vignette (Vignette 3) as a stronger test for responsiveness in a real-world setting. The issue at hand is the number of Temporary Foreign Workers (TFW) allowed in Canada. In contrast to Vignettes 1 and 2, we did not clearly signal the 'good policy' option and were aware that respondents' prior beliefs would influence their decision. As a result, we may expect weaker effects for this vignette. Our dependent variable for this vignette is scaled so that ' 1 ' indicates very strong opposition to program expansion, and ' 0 ' represents very strong support.

For each of the three vignettes, respondents were randomly assigned into one of three or four experimental groups. ${ }^{5}$ The vignettes hold constant all of the information about the policy and the

\footnotetext{
${ }^{5}$ Randomization was successful across important covariates as displayed in Table A1 of the supplementary materials. Respondents were asked three attention check questions related to the vignettes and were excluded from the experimental analysis if they failed all three (17\%).
} 
decision-making environment across groups save for the estimated state of future opinion. Vignette 1 required a choice between two options labelled 'Jump Start' and 'Fast Finish' with the latter option supported by the civil service and ideological allies. The control group, learned that the issue is high on the public's agenda and that the current polls indicate strong support for Jump Start over the 'good policy' option (Fast Finish). Respondents in the treatment groups learned that future public opinion was either going to turn positive or continue to be negative and have either high or low future salience if it continued to be negative.

Anticipated salience is the sole focus of the second vignette (Vignette 2) which discusses policy options 'Aspire' and 'Secure'. The control group received the control condition which contained the vignette, information indicating that the general public was strongly against the 'good policy' option, Aspire, and that the issue was currently very salient. Respondents in the treatment groups learned that issue salience was going to remain high in the future or drop considerably with no mention of the direction of opinion.

Our general expectations for Vignette 1 is that support for the good policy option should be higher when future opinion turns positive towards that position and lower when support remains negative regardless of salience if respondents are unconditionally responsive to future opinion (H1). We also might expect support for the good policy option to vary with future salience if responsiveness is conditional (H2). It might rise with low salience and fall with high salience. Our expectation is weaker here since the information in this treatment maintains the negative, salient disposition of public opinion from the control condition. It hinges on an assumption that respondents do not use current opinion to infer future opinion. However, as many of our respondents noted, this sometimes happens in the absence of other information, so we might not observe a significant difference. This also applies to our expectations about the negative/salient group in Vignette 2. Conditional responsiveness (H2) would also lead us to expect more support for the good policy opinion in the non-salient condition of Vignette 2, and less support in the salient condition.

The final vignette randomly assigned respondents into three groups (Vignette 3). The control condition read a vignette noting that current public opinion is ambivalent between increasing and maintaining the number of temporary foreign workers in Canada. Respondents in the treatment conditions learned that public opinion would turn against program expansion, with one group hearing it would be salient and another that it would be non-salient. Unconditional responsiveness would lead us to expect more opposition to program expansion in both treatment groups (H1), while conditional 
responsiveness would expect it only in the salient condition (H2). Expectations for our vignettes based on our hypotheses are laid out in Table 3.

To summarize, respondents first answered questions on their political experience and background and then read and responded to each vignette in turn (the order of Vignettes 1 and 2 was randomized). After the experiments, respondents answered questions on the role of public opinion in policy making, the relative importance of current and future opinion, and the information sources they use to form expectations about future opinion.

Table 3. Expectations for Vignettes based on Hypotheses

\begin{tabular}{|c|c|c|c|c|c|c|}
\hline Vignette & Expectation & Hypothesis & Treatment & Control & Diff. & P-value \\
\hline \multirow{4}{*}{1} & Support $>$ Control* & $\mathrm{H} 1 / \mathrm{H} 2$ & $0.88(37)$ & $0.65(28)$ & 0.23 & 0.00 \\
\hline & $\begin{array}{l}\text { Oppose/Non- } \\
\text { salient < Control }\end{array}$ & $\mathrm{H} 1$ & \multirow{2}{*}{$0.79(36)$} & \multirow{2}{*}{$0.65(28)$} & \multirow{2}{*}{0.15} & \multirow{2}{*}{0.02} \\
\hline & $\begin{array}{c}\text { Oppose/Non- } \\
\text { salient }>\text { Control } *\end{array}$ & $\mathrm{H} 2$ & & & & \\
\hline & $\begin{array}{l}\text { Oppose/Salient } \\
<\text { Control }\end{array}$ & $\mathrm{H} 1 / \mathrm{H} 2$ & $0.66(27)$ & $0.65(28)$ & 0.01 & 0.89 \\
\hline \multirow{2}{*}{2} & $\begin{array}{l}\text { Oppose/Non- } \\
\text { salient }>\text { Control* }\end{array}$ & $\mathrm{H} 2$ & $0.46(47)$ & $0.35(36)$ & 0.11 & 0.09 \\
\hline & $\begin{array}{l}\text { Oppose/Salient } \\
<\text { Control }\end{array}$ & $\mathrm{H} 2$ & $0.36(45)$ & $0.35(36)$ & 0.01 & 0.95 \\
\hline \multirow{3}{*}{3} & $\begin{array}{l}\text { Oppose/Salient } \\
>\text { Control* }\end{array}$ & $\mathrm{H} 1 / \mathrm{H} 2$ & $0.56(43)$ & $0.43(42)$ & 0.13 & 0.05 \\
\hline & $\begin{array}{l}\text { Oppose/Non- } \\
\text { salient }>\text { Control }\end{array}$ & H1 & \multirow{2}{*}{$0.44(43)$} & \multirow{2}{*}{$0.43(42)$} & \multirow{2}{*}{0.01} & \multirow{2}{*}{0.84} \\
\hline & $\begin{array}{c}\text { Oppose/Non- } \\
\text { salient }=\text { Control }\end{array}$ & $\mathrm{H} 2$ & & & & \\
\hline
\end{tabular}

Note: * indicates expectation was met in hypothesis testing. H1 is the unconditional responsiveness hypothesis. $\mathrm{H} 2$ is the conditional responsiveness hypothesis. 2/5 expectations met for $\mathrm{H} 1,5 / 7$ expectations met for $\mathrm{H} 2$. Estimates are the group means for the 0-1 dependent variable scale where 1 indicates 'very strong' support for the "good public policy" option and 0 is 'very strong' for the other policy. Sample sizes in paretheses after excluding respondents who failed all three screener questions.

\section{Experimental Results}

In Vignettes 1 and 2 the dependent variable is a 0-1 scale where 1 indicates 'very strong' support for the "good public policy" option and 0 is 'very strong' for the other policy. In Vignette 3 it ranges from 'very strong' support for increasing TFW to 'very strong' support for the status quo. Before addressing the empirical tests for our hypotheses, one result is worth mentioning. The means of the 
control condition in both Vignette $1(0.65)$ and Vignette $2(0.35)$ indicate a fair degree of responsiveness to current opinion. We designed the vignettes to make the choice to support the 'good policy' fairly easy. We thus expect that absent concern about public opinion most respondents will strongly support these policies; and thus the mean should be close to one. A departure from that number indicates responsiveness to current public opposition.

All told, we find comparatively stronger evidence that responsiveness to future opinion is conditional on future salience (H2) rather than unconditional (H1). Table 3 displays the results of our hypothesis testing in full. In Vignette 1, learning that the public would come to support the 'good policy' option moves recommendations in that direction. Compared to the control, which includes no information on estimated future opinion, support for the 'good policy' increases by 0.23 points from 0.65 in the control to 0.88 in the positive future opinion category. This difference is large, $23 \%$ of a 0-1 scale, and statistically significant $(\mathrm{p}<0.01$, one-tailed). This is consistent with H1, but it was an easy test. Respondents moved in the direction of estimated future opinion when it was consistent with their preferences.

Respondents also expressed more support for the 'good policy' option when it was revealed future opinion would likely be negative but would fade in importance for voters compared to the control condition (oppose/non-salient $=0.79$ vs. control=0.65). This difference of 0.15 points is statistically significant ( $\mathrm{p} \sim 0.02$, one-tailed). This finding is consistent with our conditional hypothesis (H2), but not the unconditional variant (H1). Interestingly, there is no significant difference between the treatment condition where respondents believed future opinion would be negative towards the 'good policy' option and salient (oppose/salient $=0.65$ vs. control=0.66, Diff $=0.01, \mathrm{p} \sim 0.89$ ). That is, learning of continued salient opposition has no additional impact on policy support. This result is consistent with the possibility that respondents in the control condition, who had no information about future opinion, assumed opinion stability.

Results from the second vignette also offer some support for our conditional hypothesis (H2). Recall that public opinion measured at the time of the policy choice indicated clear opposition to the 'good policy' option. When informed that the issue would fade on the public's agenda, respondents were more likely to embrace the 'good policy' option (non-salient $=0.46$ vs. control=0.35). This difference of 0.11 points is marginally significant ( $p \sim 0.09$, one-tailed). Again, however, telling respondents that future public opinion on the issue would remain unchanged had no added effect in influencing policy recommendations (salient $=0.36$ vs. control $=0.35$, Diff $=0.01, p \sim 0.95$ ), another 
indication that policy makers may infer future public opinion from current opinion in the absence of other information. Future work should examine this possibility with additional experimental vignettes.

Our more realistic policy scenario in Vignette 3 again demonstrates that issue salience moderates the impact of future opinion. Learning that the public support for increasing temporary foreign workers would move from ambivalence to opposition has no impact on policy choices when estimated future salience is low (oppose/non-salient $=0.44$ vs. control=0.43, Diff=0.01, $\mathrm{p} \sim 0.84$ ). In sharp contrast, policy advisors were more opposed to TFW expansion when told future opinion would be negative and highly salient (oppose/salient $=0.56$ vs. control $=0.43$ ). This difference of 0.13 points is statistically significant ( $\mathrm{p} \sim 0.05$, one-tailed). Being informed that future opinion would likely oppose a decision only affected respondents when they were told future opinion would also be salient, providing strong support for $\mathrm{H} 2$.

\section{Discussion}

Accounting for the anticipated direction and salience of public opinion is crucial for scholars who are interested in public opinion as an input into the policy process. Studying this is no easy task. The effects of current and estimated future opinion need to be disentangled, along with the direction and salience of that opinion. As a result, little work has explored this dimension of policy responsiveness. Our contribution is in providing both a novel experiment on a unique sample of elites and closed and open-ended survey questions to tell us a compelling story of how public opinion factors into the policy making process.

Our sample of former Canadian policy advisors provides fascinating insight into the role of current and anticipated election-proximate public opinion in the policy process. Respondents indicated public opinion can play a considerable role in policy decisions. However, current public attitudes towards policy are not seen as significant unless they relate to a highly-charged issue at election time. For the rest of a government's mandate, respondents believe policy makers had to make a choice to lead or follow the public - both of which require an estimate about how the public will feel about the policy or the government after the cut and thrust of political debate.

Policy responsiveness to public opinion is, however, conditional on issue attention. Our political advisors do not feel that public opinion is an important factor in areas of low issue attention, which comprise the majority of policy issues. Anticipating the public's agenda around the next election, however, is seen to be fraught with difficulty. Our respondents appear to derive their estimates about the future direction and salience of opinion primarily from expected policy impacts, interest group 
positions, and the fit between the policy and the leader's brand. In short, our elite sample of policy advisors reveal nuanced judgments on the role of public opinion in policy making. And, importantly for our purposes, our respondents believe that public opinion is dynamic and that it is a relatively common practice to (imperfectly) anticipate public opinion - both its direction and agenda - based on a wide variety of heuristics that are available to them.

Our novel experimental design provides evidence of causality to back up these claims. The results show that policymakers are responsiveness to expectations of future opinion across both simulated and real policy issues. However, this responsiveness is conditional on high estimated salience, which is consistent with our conditional responsiveness hypothesis (H2). Policy makers fail to bend to expectations of future opinion when they think they can get away with pursuing their preferences. None of this means that policy makers never respond to current public opinion. The average policy recommendations in our first two vignettes suggest meaningful responsiveness to current opinion - either because they use it to infer future opinion, as our results seem to suggest, or because they see it as important in its own right. Future research should unpack further how policy makers balance current public opinion with their expectations of future opinion, closer to election time.

There are, of course, important limitations to our design. First, we aimed to prioritize the identification of a causal effect, so our experimental manipulation of anticipated future opinion stripped our vignettes of many elements of the political context that respondents could use to read in their own estimates of future opinion. We did this to clearly hone in on the mechanism. The broader context, however, does matter. In the open-ended responses to our survey, respondents hint at using certain latent propensities in public attitudes to estimate future opinion, such as the tendency of the public to oppose policies with visible costs, particular for small, vocal groups of citizens. It is these latent propensities that interest Zaller (2003). They also emphasized the dynamic properties of opinion formation that were ultimately contingent on the communication strategies of both themselves and the opposition. This is of interest to Key (1961): what happens to public opinion after both sides have made their case, if they choose to do so? Future experiments should manipulate details of the political context to expose the importance of these latent propensities and dynamics in shaping policy decision making.

There are also implications of our prioritization on identifying causal effects for the generalizability of our results. We cannot make confident assertions about how strong these effects would be in real world scenarios. Vignette 3 moved us closer towards being able to generalize to such 
situations with its use of a real issue currently debated in Canadian politics, but ultimately this represents a weakness of even the best designed lab or survey experiment. Nevertheless, consistent results across both the simulated and real policy issues suggest we are indeed tapping into the mechanism of responsiveness to future opinion direction and salience. Further, this finding is echoed by oftentimes frank insights our elite respondents offered. As a result, we strongly suspect this policy makers often seek to anticipate future opinion.

Second, insights from open-ended survey responses suggest we could have done more to magnify the power of our treatments. For example, manipulations feature information from a 'trusted pollster', despite many respondents indicating skepticism about this information source. If many respondents viewed pollster estimates as a relatively unhelpful signal, this feature of our design biases our results toward zero. Future studies might explore the relative impact of different sources of future opinion estimates as well as varying the timing of a policy decision in the electoral cycle and the openness of the public to persuasion on the issue. In short, insights from our respondents can be used to design more compelling experimental vignettes.

Finally, our sampling technique limits our ability to confidently generalize beyond our sample of respondents. However, our descriptive measures are only weakly correlated with ideology, experience, and occupation. There is also little evidence that our treatment effects vary with each of these factors. Further, the modest size of our sample limited the number of treatment arms we could employ. As such, a fuller account of responsiveness to current and future opinion awaits additional research and larger samples. In short, additional elite experiments, along the lines of those presented here, can further our understanding of the basic relationships at play and how these relationships vary across political contexts.

Our participants emphasized the importance of context in understanding how public opinion influences policy. We could not agree more. Beyond measuring correlations between polling data and policy outcomes, future research needs to better account for the characteristics and conditional role public opinion plays in policy-making. Surveying elites can provide the means by which this is accomplished. Only then can our assessments of democratic responsiveness accurately account for the crucial insights V.O. Key and John Zaller laid out.

\section{References}

Achen, C., \& Bartels, L. (2016). Democracy for realists: Why elections do not produce responsive government. Princeton: Princeton University Press. 
Bartels, L. (2008). Unequal democracy: The political economy for the New Gilded Age. Princeton: Princeton University Press.

Baumgartner, F. R., \& Jones, B. D. (1993). Agendas and instability in American politics. Chicago: University of Chicago Press.

Blidook, K. (2010). Exploring the role of 'legislators' in Canada: Do Members of Parliament influence policy. The Journal of Legislative Studies, 16(1), 32-56. doi: 10.1080/13572330903541979

Blidook, K. (2012). Constituency influence in Parliament: Countering the centre. Vancouver: UBC Press.

Broockman, D., \& Skovron, C. (2018). Bias in perceptions of public opinion among political elites. American Political Science Review, 112(3), 542-563. doi: 10.1017/S0003055418000011

Burstein, P. (2003). The impact of public opinion on public policy: A review and an agenda. Political Research Quarterly, 56(1), 29-40. doi: 10.1177/106591290305600103

Butler, D. M., \& Nickerson, D. W. (2011). Can learning constituency opinion affect how legislators vote? Results from a field experiment. Quarterly Journal of Political Science, 6(1), 55-83. doi: $10.1561 / 100.00011019$

Dahl, R. A. (1971). Polyarchy: Participation and opposition. New Haven: Yale University Press.

Daw, J. R., Morgan, S. G., Thomson, P.A., \& Law, M. R. (2013). Here today, gone tomorrow: The issue attention cycle and national print media coverage of prescription drug financing in Canada. Health Policy, 110(1), 67-75. doi: 10.1016/j.healthpol.2013.01.006

Downs, A. (1972). Up and down with ecology: The issue-attention cycle. Public Interest, 28, 38-50.

Erikson, R. S. (2015). Income inequality and policy responsiveness. Annual Review of Political Science, 18(1), 11-29. doi: 10.1146/annurev-polisci-020614-094706

Erikson, R. S., Mackuen, M. B., \& Stimson, J. A. (2002). The macro polity. New York: Cambridge University Press.

Faugier, Jean, \& Sargeant, M. (1997). Sampling hard to reach populations. Journal of Advanced Nursing, 26(4), 790-797. doi: 10.1046/j.1365-2648.1997.00371.x

Fiorina, M. (1981). Retrospective voting in American national elections. New Haven: Yale University Press.

Franks, C.E.S. (1987). The parliament of Canada. Toronto: University of Toronto Press.

Gilens, M. (2005). Inequality and democratic responsiveness. Public Opinion Quarterly, 69(5), 778-796. doi: $10.1093 / \mathrm{poq} / \mathrm{nfi} 058$

Gilens, M., \& Page, B. I. (2014). Testing theories of American politics: Elites, interest groups, and average citizens. Perspectives on Politics, 12(3), 564-581. doi: 10.1017/S1537592714001595 
Godbout, J., \& Høyland, B. (2013). The emergence of parties in the Canadian House of Commons (1867-1908). Canadian Journal of Political Science, 46(4), 773-797. doi: $10.1017 / \mathrm{S} 0008423913000632$

Goodman, L. A. (1961). Snowball sampling. The Annals of Mathematical Statistics, 32(1), 148-170.

Griffiths, P., Gossop, M., Powis, B., \& Strang, J. (1993). Reaching hidden populations of drug users by privileged access interviewers: Methodological and practical issues. Addiction, 88(12), 16171626. doi: 10.1111/j.1360-0443.1993.tb02036.x

Herbst, S. (1993). Numbered voices: How opinion polling as shaped American politics. Chicago: University of Chicago Press.

Holt, D., \& Barkemeyer, R. (2012). Media coverage of sustainable development issues: Attention cycles or punctuated equilibrium. Sustainable Development, 20(2), 1-17. doi: 10.1002/sd.460

Jacobs, L. R., \& Shapiro, R. Y. (2000). Politicians don't pander: Political manipulation and the loss of democratic responsiveness. Chicago: University of Chicago Press.

Kam, C. (2009). Party discipline and parliamentary politics. Cambridge: Cambridge University Press. Key, V.O. (1961). Public opinion and American democracy. New York: Alfred A. Knopf.

Lax, J. R., \& Phillips, J. H. (2009). Gay rights in the states: Public opinion and policy responsiveness. American Political Science Review, 103(3), 367-386. doi: 10.1017/S0003055409990050

Mayhew, D. (1974). Congress: The electoral connection. New Haven: Yale University Press

Miller, J. M., Krosnick, J. A., \& Fabrigar, L. R. (2016). The origins of policy issue salience: Personal and national importance impact on behavioral, cognitive, and emotional issue engagement. In J. A. Krosnick, I. A. Chiang, \& T. H. Stark (eds.), Political Psychology: New Explorations (pp. 125171). New York: Psychology Press.

Mueller, J. (1973). War, presidents, and public opinion. New York: Wiley Press.

Mueller, J. (1994). Policy and opinion in the Gulf War. Chicago: University of Chicago Press.

Nyhan, B., \& Reifler, J. (2015). The effect of fact-checking on elites: A field experiment on U.S. state legislators. American Journal of Political Science, 59(3), 628-640. doi: 10.1111/ajps.12162

Page, B. I., \& Shapiro, R. Y. (1983). Effects of public opinion on policy. American Political Science Review, 77(1), 175-190. doi: 10.2307/1956018

Petersen, K. K. (2009). Revisiting Downs' issue-attention cycle: International terrorism and U.S. public opinion. Journal of Strategic Security, 2(4), 1-16. doi:10.5038/1944-0472.2.4.1

Polsby, N. W. (1975). Legislatures. In F. Greenstein \& N. Polsby (eds.), Handbook of Political Science: Governmental Institutions and Processes, vol. 5 (pp. 275-319). Reading, MA: Addison-Wesley. 
Powlick, P. J. (1995). The sources of public opinion for American foreign policy officials. International Studies Quarterly, 39(4), 427-451. doi: 10.2307/2600801

Quirk, P. J. (1988). In defense of the politics of ideas. The Journal of Politics, 50(1), 31-41. doi: $10.2307 / 2131039$

Savoie, D. (2008). Court government and the collapse of accountability in Canada and the United Kingdom. Toronto: University of Toronto Press.

Shapiro, R. Y. (2015). Public opinion and American democracy. Public Opinion Quarterly, 75(5), 9821017. doi: $10.1093 / \mathrm{poq} / \mathrm{nfr} 053$

Sheffer, L., \& Loewen, P. (2019). Linking electoral confidence, overconfidence, and risky behaviour: Evidence from a study with elected politicians. Political Behavior, 41(1), 31-51. doi: $10.1007 /$ s11109-017-9438-0

Soroka, S. N. (2007). Agenda-setting and issue definition. In M. Orsini \& M. Smith (eds.), Critical Policy Studies (pp. 185-210). Vancouver: UBC Press.

Soroka, S. N., \& Wlezien, C. (2005). Opinion-policy dynamics: Public preferences and public expenditure in the UK. British Journal of Political Science, 34(4), 665-689. doi: $10.1017 / \mathrm{S} 0007123405000347$

Soroka, S. N., \& Wlezien, C. (2010). Degrees of democracy: Politics, public opinion, and policy. Cambridge: Cambridge University Press.

Stimson, J. A., Mackuen, M. B., \& Erikson, R. S. (1995). Dynamic representation. American Political Science Review, 89(3), 543-565. doi: 10.2307/2082973

Thomas, P. (2010). Parliament and legislatures: Central to Canadian democracy?” In J. C. Courtney \& D. E. Smith (eds.), Oxford Handbook of Canadian Politics. Oxford: Oxford University Press. Thomson, S. K. (1997). Adaptive sampling in behavioural surveys. NID A Research Monograph, 296319.

Walgrave, S., Sevenas, J., \& Loewen, P. (2018). What draws politicians' attention? An experimental study of issue framing and its effect on individual political elites. Political Behavior, 40(3), 547569. doi: 10.1007/s11109-017-9413-9

Wlezien, C. (2005). On the salience of political issues: The problem with 'most important problem.' Electoral Studies, 24(4), 555-579. doi: 10.1016/j.electstud.2005.01.009

Zaller, J. (1995). Strategic politicians, public opinion, and the Gulf War. In L. W. Bennett \& D. Paletz (eds.), Taken by Storm: The News Media, U.S. Foreign Policy, and the Gulf War (pp. 186-209). Chicago: University of Chicago Press. 
Zaller, J. (2003). Coming to grips with V.O. Key's concept of latent opinion. In M. MacKuen \& G. Rabinowitz (eds.), Electoral Democracy (pp. 311-336). Ann Arbor: University of Michigan Press. 